\title{
Management accounting change in a subsidiary organisation
}

\author{
Hassan Yazdifar ${ }^{\mathrm{a}, *}$, Mahbub Zaman ${ }^{\mathrm{b}}$, \\ Mathew Tsamenyi ${ }^{\mathrm{a}}$, Davood Askarany ${ }^{\mathrm{c}}$ \\ ${ }^{a}$ University of Sheffield, Management School, 9 Mappin Street, Sheffield S1 4DT, UK \\ ${ }^{\mathrm{b}}$ University of Manchester, Manchester Business School, Booth Street West, Manchester M15 6PB, UK \\ ${ }^{\mathrm{c}}$ University of Auckland, Faculty of Business \& Economics, Tamaki Campus Building 723, \\ Cnr Merton \& Morrin Roads, Glen Innes, Auckland, New Zealand
}

Received 8 October 2005; received in revised form 9 June 2006; accepted 12 August 2006

\begin{abstract}
Parent-subsidiary relationships are commonplace nowadays, yet surprisingly there is a paucity of research analysing their dynamics over time. This paper presents a (longitudinal) case study, illuminating the dynamics implicated when a UK chemicals company imposed its systems and rules on a new subsidiary. Drawing on observations from a longitudinal case study (from 1993 to 2001), the study considers: (1) the extent to which a parent imposes its (management accounting) systems, rules and procedures on a subsidiary; (2) the role which (local) political, cultural and institutional factors in a subsidiary play in shaping the dynamics of such change implementation; (3) how new systems and practices become accepted and take root as values and beliefs and how they supplement earlier norms? The study provides insight for the questions above, and draws on institutional theories and a power mobilisation framework to assist in the interpretation of observations. We find that the operations of the subsidiary company are influenced by inter-related forces, both inside and outside the organisation encompassing issues of power, politics and culture. As such, existing institutions in a subsidiary organisation are influenced, sustained, and changed by the socio-economic context in which the subsidiary is located. Organisational practices designed to secure external legitimacy are not however always symbolic and decoupled from internal operations.
\end{abstract}

(C) 2006 Elsevier Ltd. All rights reserved.

Keywords: Management accounting; Parent; Subsidiary; Multi-institutional theory; Power; Politics

\footnotetext{
* Corresponding author. Tel.: +44 114222 3433; fax: +44 1142223348.

E-mail addresses: H.Yazdifar@sheffield.ac.uk (H. Yazdifar), Mahbub.Zaman@mbs.ac.uk (M. Zaman), M.Tsamenyi@sheffield.ac.uk (M. Tsamenyi), D.Askarany@auckland.ac.nz (D. Askarany).
} 


\section{Introduction}

This paper investigates why and how management accounting systems (MAS) in a subsidiary company emerge, are sustained, and change over time. Drawing upon theoretical insights from new institutional sociology (NIS), old institutional economics (OIE) and power perspective (Hardy, 1996), this paper focuses on management accounting change in a group organisation. The multi-theoretical framework and empirical focus on the parent-subsidiary context in this paper, which has been largely unexplored in the management accounting literature (Granlund, 2003), is particularly novel and represents a significant contribution.

In the 21st century, parent-subsidiary relationships are commonplace. However, the extant research in this area predominantly adopts a static view of such relationships (Johanson and Vahlne, 1977; Jones, 1985, 1992; Vernon, 1966), and has focused on the complexity of change at parent company level rather than giving consideration to the subsidiary level as well (Kostova and Roth, 2002). To date, there is little understanding of the reasons why subsidiary organisations choose to retain or change their (accounting) systems (Granlund, 2003; Jones, 1985, 1992; Vamosi, 2000) and of how a change programme such as change in MAS should take place following mergers and acquisitions (M\&A) (Granlund, 2003; Jones, 1985). Jones $(1985,1992)$ emphasises there is little understanding of the processes of why and how new MAS have emerged (or failed to emerge) in subsidiary organisations over time. Furthermore, the management accounting (MA) choice literature tends to lie in the market theory camp, which argues that firms select their MAS according to a rational economic cost-benefit calculus. Indeed, as Granlund (2003, p. 208) states, M\&A "have rarely been analysed from management accounting's point of view, and this is especially so if we are looking for studies that try to understand the human and social aspects of these processes". Interesting research questions abound, which are examined in this paper. For instance, to what extent does a parent organisation impose its rules, procedures, and/or systems (including management accounting) on a subsidiary, and how? How important are (local) political, cultural, and institutional factors in shaping the dynamics of such change implementation? How do new systems and practices (e.g., management accounting) become accepted and take root as values and beliefs and how do they supplement earlier norms?

As already alluded to, this paper aims to contribute towards the shortfall in our knowledge of parent-subsidiary relationship dynamics and MA change in group organisations, using observations from a longitudinal case study. The study adopts an interpretative, (multi) institutional theory (Burns and Scapens, 2000; DiMaggio and Powell, 1991; Scott, 2001) alongside a power mobilisation framework (Hardy, 1996), to assist in the analysis of the development of the processes (emergence, continuity, change, etc.) of new and old rules, procedures and systems that underpin the relationship dynamics in the case study. Overall, it contributes towards furthering our understanding of parent-subsidiary dynamics and highlights the need for bridge building between (institutional) theories to expand levels of analysis.

The paper is structured as follows. As a starting point, the two sections below provide the theoretical background (including details key concepts used to structure the analysis) and methodological issues relevant to the study. The following two sections present the 
background of parent and the subsidiary companies, respectively. Then, the paper analyses the takeover process and discusses how the parent company had instigated a radical change in the ways of thinking and doing things in the subsidiary. The next section presents the subsidiary's situation after the takeover. The paper ends with a summary and discussion of the key findings.

\section{Theoretical framework: towards a pluralistic dialogue}

Stimulated by the challenge to conventional wisdom and the prevailing research beliefs that assert that organisations are bounded, relatively autonomous, and made up of rational actors (Abernethy and Chua, 1996), a growing number of organisational researchers have adopted institutional perspectives to conceptualise and explain management accounting change (see for example Berry et al., 1985; Carpenter and Feroz, 1992; Covaleski and Dirsmith, 1988; Covaleski et al., 1993; Mezias, 1990). New institutional sociology, for instance, views organisations as being embedded within larger inter-organisational networks and cultural systems. This institutional environment not only influences the organisation's input and output markets, but also its beliefs, norms, and historical traditions. Furthermore, the institutional environment is characterised by the elaboration of rules, practices, symbols, beliefs, and normative requirements to which individual organisations must conform to receive support and legitimacy. The success of an organisation from an NIS perspective is defined by the extent to which it embodies societal 'ideals' (myths) regarding norms of rational behaviour (see Scott, 2001).

Some institutional sectors or fields contain environmental agents that are sufficiently powerful to impose structural forms and/or practices on subordinate organisational units (Scott, 1987). In addition to nation-states, which "do this when mandating by law changes in existing organisational forms or when creating a new class of administrative agencies", Scott (1987, p. 501) explicitly mentions 'corporations' as cases which routinely do this when, for example, structural changes are imposed on companies that have been acquired or when existing subsidiaries are reorganised. Therefore, through the lens of NIS, subsidiary companies are subject to environmental pressures exerted by their constituencies, amongst them parent companies in particular. Of particular relevance to the focus of this paper, in a parent company setting, parents often exert influence by means of authority. As Scott (1987) notes in NIS, the adoption of parent companies' systems by its subsidiaries (for example, Group and Omega in this study) is fundamentally a means by which subsidiary companies conform with the demands and expectations of their parent companies-rather than, say, overriding aims for cost-minimisation as is the basic assumption in conventional wisdom and new institutional economics.

\subsection{The concepts of NIS theory}

The central tenet of NIS is that organisations are pressured to become isomorphic with, or conform to a set of institutionalised beliefs (Scott, 1987). DiMaggio and Powell (1991) identify three mechanisms through which institutional isomorphic change occurs, each with its own antecedents. The first is coercive isomorphism, which stems from political influence 
and the problem of legitimacy. It is the response to "both formal and informal pressures exerted on organisations by other organisations upon which they are dependent and by cultural expectations in the society within which organisations function" (DiMaggio and Powell, 1991, p. 66). The second mechanism is mimetic isomorphism, which occurs when organisations face uncertainty and model themselves on other organisations. Organisations will tend to copy those organisations in their organisational field that are perceived to be more legitimate (e.g., parent company) or successful or those outside their organisational field that are similar to themselves in complexity. The third mechanism is normative isomorphism which is "associated with professionalization" (DiMaggio and Powell, 1991) and "arises when professionals operating in organisations are subject to pressures to conform to a set of norms and rules developed by occupational/professional groups" (Abernethy and Chua, 1996, p. 574).

Despite its current vogue in organisational analyses NIS is not without problems. First, NIS is frequently criticised for its deterministic nature and its neglect of the role of active agencies and issues of power and interest at the micro-level (Carmona et al., 1998). This in turn, stems from the theory's rejection of rational choice models of human action. The concern expressed by Powell (1991, p. 194) is that NIS 'portrays organisations too passively and depicts environments as overly constraining' (see Oliver, 1992). According to Zucker (1991, p. 105), NIS researchers risk treating institutionalisation as a "black box at the organizational level" without solid cognitive micro-level foundations. Second, the assumption that practices designed to secure external legitimacy are only symbolic and always decoupled from internal operating systems has been seriously questioned (Abernethy and Chua, 1996; Carruthers, 1995; Mouritsen, 1994; Zucker, 1987). Third, the theory does not consider the path of change in the organisational realm; rather, it focuses on change at an extraorganisational level (Dillard et al., 2004). Zucker (1991, p. 106) also comments, "Institutional theory is always in danger of forgetting that labelling a process or structure does not explain it". DiMaggio (1988) argues that institutional theory does quite poorly at understanding the role of agency in the creation, maintenance, and demise of institution.

These criticisms indicate that the theory suffers from 'inadequate consideration of the relationship between environment/institutional determinism (e.g., parent companies) and cultural and political factors within (subsidiary) organisations. NIS thus needs to be complemented by other perspectives, one which factors internal organisational dynamics into NIS explanation (DiMaggio, 1988; Fligstein, 1989; Scott, 1987; Zucker, 1988).

One theory that could enhance NIS's capacity to analyse the complex dynamics of change at micro-level and explain conflict and actors' struggle for power could be OIE. Thus, in order to adopt a holistic framework, we propose a "hybrid" framework blending NIS and OIE (see below). This allows us to examine organisational responses to the institutional environment while relaxing the assumption that these primarily follow a pattern of passive acquiescence in the search for conformity and legitimacy (Modell, 2001). To illuminate further the dynamics of the processes of change in the subsidiary company, insights from NIS and OIE are complemented by drawing on frameworks of power mobilisation developed by Hardy (1996). This hybrid approach assists in theorising why and how processes of (management accounting) change in the subsidiary company unfolded through time. 


\subsection{The concepts of OIE theory}

From an OIE perspective, accounting change can be understood in terms of change in accounting routines that may (or may not) be embedded in the taken-for-granted assumptions and beliefs of an organisation. Such assumptions and beliefs, common to organisational members, are called 'institutions' and are typically defined as "a way of thought or action of some prevalence and permanence, which is embedded in the habits of a group or the customs of a people" (Hamilton, 1932, p. 84). Routines, on the other hand, comprise "programmatic', rules-based behaviour that is grounded in repeatedly following such rules. Over time, routines become increasingly underpinned by tacit knowledge individuals acquire through reflexive monitoring of past behaviour. Routines are thus the habits of a group, for example, the members of an organisation, and the 'components' of institutions (Hodgson, 1993).

Burns and Scapens (2000, p. 11) argue that the process of institutionalisation "involves a dissociation of patterns of behaviour from their particular historical circumstances", so that routines take on a normative and factual quality, which obscures their relationship with particular interests or interests of the different actors. In other words, the rules and routines become simply the way things are, i.e., institutions. These institutions will then be encoded into the ongoing rules and routines and will shape new rules, and so on. The more widely and deeply the institution is accepted, the more likely it is to influence action and to resist change. As such, institutions are the structural properties which comprise the taken-forgranted assumptions about the way of doing things, which shape and constrain the rules and routines, and determine the meanings, norms, values, and also powers of the individual actors.

Burns and Scapens (2000) apply such theoretical concepts to suggest how accounting practices can become routinised (see also Nelson and Winter, 1982) and, in time, begin to constitute part of the taken-for-granted assumptions and beliefs in an organisation. From this viewpoint, accounting practices and emerging routines can be said to be institutionalised when they become widely taken-for-granted in the organisations to the extent that they become the unquestionable form of management control. Thus, OIE insight is useful for conceptualising the continuity of accounting over time, though such continuity can change. However, the above is not to say that all accounting becomes routinised and institutionalised, but that there is a potential for routinisation and institutionalisation to occur, as well as change in these settled ways (Burns, 2000b).

Drawing on OIE, Burns and Scapens (2000, pp. 20-21) distinguish between ceremonial and instrumental behaviour and suggest that accounting routines can be institutionalised in a ceremonial or instrumental way. Ceremonially institutionalised accounting routines are organisational rituals, which are used to preserve the status quo and the existing power or interests of specific groups or individuals, rather than to aid decision-making. Whereas, instrumentally institutionalised accounting routines are used to make informed decisions and seeks to enhance relationships. Whether accounting is institutionalised ceremonially or instrumentally depends on the wider institutional setting within the organisation; accounting routines both shape and are shaped by other institutions. Hence, how management accounting is practised, how accounting information is used, and the role of accountants, depend on the institutions within the organisation (Siti-Nabiha and Scapens, 2005, p. 47). 
For OIE researchers, the adoption or rejection of parent companies' systems by subsidiary companies should be studied in relation to historical, cultural, social, and political issues that are relevant to the comprehension of organisational change in its full complexity (Scapens, 1991). Such institutionalists contend that the adoption of a parent company's systems by its subsidiaries might be a source of conflict and resistance. The implementation of new (MA) systems will succeed to the extent that there is broad congruence between the new systems (rules) and existing routines and taken-for-granted assumptions in the subsidiary companies.

In brief, an institutional framework, incorporating both OIE and NIS, can be adopted as a theoretical framework to explain how institutions (at macro- and micro-levels) shape and constrain the behaviour and actions of individuals and organisations and to analyse how individuals, in turn, modify and transform the institutions and organisations. Therefore, by taking this perspective, the analysis may provide a more holistic picture of various organisational phenomena, such as change in MAS.

\subsection{The concepts of power mobilisation}

Hardy (1996) developed a framework of power encompassing four dimensions as follows.

Power over resources depicts where actors deploy (or restrict) key resources (e.g., information, political access, creditability, access to higher echelon members, control of money, rewards, and sanctions) to modify the behaviour of others. It tends to be 'task-oriented' and often involves 'carrot and stick' persuasion and/or coercion. Power over decisionmaking processes is exerting power over subordinates' participation in decision-making processes-i.e., by preventing subordinates' participation and/or enhancing participation. Such manipulation of power permits the powerful actors to determine outcomes from 'behind the scenes'. Power over meaning is influencing actors' perceptions, cognitions and/or preferences in order that they accept the status quo (failing to recognise alternatives) or, become convinced that change is 'desirable', 'rational' and/or 'legitimate'. Power of the system (mirrors the notion of institution according to OIE) deeply embedded within the organisation and is supported by the 'unconscious acceptance' of existing, prevalent organisational values, cultures and structure. Such characteristics are taken-forgranted assumptions which 'capture all organisational members in its web'. These powers, and the politics underpinning them, it is argued, can be both key facilitators and/or prohibitors to the process through which new MA techniques evolve. Hardy's (1996) insights about power complements the earlier discussion about OIE which attempts to explain phenomena in 'processual' terms, analysing why and how things become what they are, or otherwise, over time. Power (i.e., 'to produce intended effects' in line with perceived interests, see Pettigrew and McNulty, 1995) and politics (i.e., "the practical domain of power in action", see Buchanan and Badham, 1999, p. 11) are also integral to any OIEgrounded explanation of life's ongoing processes-i.e., part of OIE's core methodological underpinnings.

The following case study illustrates how the above ideas are useful in unravelling the processes of MA change. 


\section{Research method}

The case study is an interpretive one, recognising that interpretations of actors take place within a particular historic, political, and economic context (Collier, 2001). It draws primarily on interview data, but also utilizes internal company documentation. The validity and reliability of our data was achieved through cross checking between transcripts and company documentation, and through feedback to interviewees. Research for the (longitudinal) case study presented below took place over an 8-year period from 1993 to 2001.

Interviews provided the main source of information - a total of 33 interviews were undertaken during the 8-year period, with 17 different people. All interviews (except two) lasted between 1 and 2 hours. These were also followed-up by some telephone and email to clarify some issues arising from the interview analysis.

All interviews were tape recorded, and then transcribed. However, interviewees were assured beforehand that the taping was aimed entirely at enhancing the research process (i.e., less need for scribbling quotes, a more complete set of records, etc.), and confidentiality was assured both externally and internally.

In addition to the transcripts, most interviewees made reference to internal documentation - for example, the management accounts and reports, operational and production reports or minutes to meetings. Copies of certain (though not all) documentation was offered to the researchers; though normally in "skeleton" form; that is, with any numbers and/or sensitive text omitted. Finally, brief notes were made during and after each interview to record "other" (informal) information and all the relevant aspects of the social process (Babbie, 1989) that had not been captured on tape-for example, "give away" facial expressions, the intonation of the voice, gestures, periods of extended silence and "off-therecord" comments, i.e., sensitive issues that were discussed without being taped. Reflections on the outcomes of the interview were also recorded. Based on leads from the preceding discussions, future possible interviewees and subsequent visits were also identified.

The interview process was iterative in that new interviews would follow a review of all the transcripts to date, as well as notes, reviews and summaries that had been written up to that point in time. From early on in the research process, the interviews arranged had emerged from issues arising in the discussions of previous visits. All interviews were "semi-structured" in that the issues to be explored (in general) were identified prior to a visit. But interviewees were constantly encouraged to "do all the talking", to further express their points of view.

As it was believed that processes of accounting change can be better understood in the context of broader (though inter-connected) organisational change (see earlier section), the range of people interviewed was intentionally wide and not limited to finance personnel. Interviews were also held with people from the parent company (CC) embraced: the MD, operations director (OD), quality, safety and environmental (QSE) director, marketing and IT managers and some of their personnel; interviews held with people in the subsidiary company embraced: the general manager, IT officer, quality controller (QC), production controller, product development officer, personnel officer and some of their personnel. Overall, interviews involved staff from all levels of the organisational hierarchy. However, as a limitation of the present research, we did not have any chance to interview people from ex-parent company (WW). 


\section{Group: the background}

Group (CC Ltd.) is a UK privately owned chemicals processor established in 1977 . The company manufactures a wide range of chemical and ancillary products for the international pharmaceutical, agrochemical, food, and allied industries. Manufacturing started at a small site in 1978 and the company grew steadily through the acquisition of further sites in 1983, 1995 and 1998, and the establishment of a sales office in the USA in 1995. Its turnover rose from $£ 1.5 \mathrm{~m}$ in 1983 to $£ 30 \mathrm{~m}$ in 2001, while employee numbers grew from 30 in 1983 to 300 in 2001. Such growth was mainly attributable to the successful export of customers' own specification products. From the early 1980s to the mid 1990s, around $80 \%$ of contribution earnings derived from contracts for specific products with individual customers (as opposed to $20 \%$ for multi-client products). Internally, these products are called "captives", reflecting the binding contract with a single customer normally over 5 years. Furthermore, captives activity was 'locked-in' (Dietrich and Burns, 2000) by factors such as their production requirement for the dedication of individual (glass) reactor-vessels to particular chemical processes which give little opportunity to alternate vessels between products in the short term.

However, 'lock-in' was fundamentally disrupted in 1988. First, due to the nature of most captive contracts, customers were able to vary their patterns of demand during the 5 -year term. Second, due to an economic recession in the late-1980s, the demand for CC's products fell quite dramatically. Third, two major captive contracts ended and were not renewed. The implication of all this for CC was near catastrophic. Production capacity became considerably under-utilized and the features of captives lock-in meant that a quick turnaround towards multi-client business was not viable in the short term.

The crisis led to an urgent review of the previously unquestioned captures lock-in policy. Having lost nearly everything, CC's board decided to redress the captives/multi-client split and a new target of a 50/50 contribution split by the mid 1990s was set. The hard lessons learned from the 1988 crisis led the company to view 1997 as crucially important because this was the year when some major captive contracts were due to terminate. The cash flow crisis in 1998 provoked a new company strategy: acquiring new companies with a portfolio of multi-client products. The acquisition of Omega in 1995, which is the focus of the present report, was part of this strategic plan. Before discussing Omega, the next section provides an overview of the group's management style and its accounting systems.

\subsection{Management style}

$\mathrm{CC}$, in addition to the technical side of the business (chemistry skills and expertise), pays special attention to the well-being of its staff. To CC, its staff are the nub of its operations and any negligence would cost the business dearly. The CC's operation director (OD) commented: "As a business, $\mathrm{CC}$ has always been people-centred and people are more important than systems".

The philosophies of CC are that a business can be successful when 'it understands its staff and its staff also understand the business'. At CC, in addition to planning and defining rules, roles, and standards, emphasis is placed on running the business with staff who knows what they are doing, why and how. To meet these 'why' and 'how' criteria, all staff are 
expected to be informed or involved in the business decision-making process, and in the corporate change programme.

\subsection{Accounting}

Accounting in $\mathrm{CC}$ is not subject to external regulations, but is an integral part of the management process and involves managers and staff from all areas of the business. Interestingly, most accounting information is produced by the managers and users themselves, rather than by those employees designated as accountants. For example, information on costs and internal management reports are produced by personnel from the Operations Department or the Production Department.

The MAS is quite simple and relies on various approximations. CC uses a standard costing system to compute the contribution earnings for each product and process. Contribution in CC is defined as sales less material cost, because materials constitute by far the largest proportion of total costs than any other item. Contribution information underpins organisation-specific 'know-how' and is part of the employees' stock of knowledge (Burns and Scapens, 2000). For example, staff at all levels, and in most departments, converse using a contributions 'language'. Contributions focus organisational members on the potential impact of their behaviour on company profits. Key performance indicators focus primarily on standard times and the contributions earnings of individual products and processes. With such background knowledge the accounting system imposed on Omega can now be further explored.

\subsection{The original intention to impose the systems on Omega}

Interestingly, although Group had carefully examined and evaluated the pre-takeover systems at Omega (see below), its initial intention was to implement the Group's systems there, to a large extent regardless of the results of the evaluation. "We obviously wanted to impose our own systems very quickly because, obviously, our managers understand our systems and how we report them", the CC's finance director stated. The CC's QSE (quality, safety and environmental) director commented. "The general idea was that we should harmonise the systems" and the CC's operations director explained that following the takeover CC "imposed something onto Omega which works [at other subsidiaries]".

Because of the group's plan and the requirement that Omega implement CC's systems, the interviewees explained their works within a few months after the takeover as mainly imitating CC's systems. Omega's IT person explained, "CC is very strict in implementing the same system at Omega. We are very much just imitating gnomes at the moment. I do feel a bit of a puppet. We just inherit their things anyway". Nine months latter, the CC's QSE director stated: "Now the management system at Omega mirrors the management systems at [other subsidiaries] in its detail".

With this acquisition, by the year $2001 \mathrm{CC}$ achieved its target of a 50/50 contribution split between captive and multi-client products, which had long been CC's aim. This change in the ratios conveys the extent of the positive contribution made by Omega to the overall Group performance. Furthermore, as the study shows CC, as well as implementing its systems and rules (e.g., data collection, input, reports, review meetings), was able to dramatically 
change the culture at $\mathrm{CC}$ and harmonise it with the group's culture, thereby removing the huge cultural differences between the companies.

To explore the reasons for this successful implementation and the cultural change, the following section provides some background information to Omega, analyses the processes of the change with regard to the past (the situation before the takeover) and the dynamics of change implementation.

\section{Omega: prior to the takeover}

The following describes some of the main features of Omega (established in the late 1960s) prior to the takeover, and includes a review of its MIS/MAS, the influence of the ex-parent company (WW), the management style, the exercise of power and politics, and also staff morale.

The IT system in Omega was managed until 1983 by an ICL system 25; following the WW takeover it was changed to the new owner's system: an MRPP incorporating manufacturing and accounts. The interviewees argued that the system was imposed by WW, the change was difficult, and people complained. Omega's IT manager described:

It was just terrible. There were so many bugs in it. It was never-ending. I was on the user committee for that and those meetings were just all the users complaining all the time.

He added, "The (new) systems were designed to meet the requirements of the parent company rather than Omega". The Omega (management) accountant stated "we reported to WW, not to our managers". Describing the users' willingness to keep the system in use, she commented, "Nobody wanted to do it really. The system was frustrating; therefore any change would be welcomed".

The interviewees argued that there was not a proper relation between activities and the accounting system, there was no proper and integrated MIS, planning and communication were weak, and consequently decision-making was done by relying on the experience of key people, and those that had power, and the potential ability to change behaviour through politics and influence (see also Collier, 2001; Pfeffer, 1992).

The problems associated with MIS and poor communications were compounded further as some individuals exercised power and engaged in politics by withholding information for their personal advantage. An interviewee argued, "There were a few people who had a huge influence on the business", who used their power to keep information for their own benefit, "to build their empires" (another interviewee affirmed). There was no exchange of information, "it was a power play position and people were doing exactly what they said". The interviewees argued that there was a lack of accountability and staff morale was very low. "The culture of the company didn't seem to lend itself to a creative thinking", affirmed Omega's QC (quality controller); "it just seemed a lot more of a slacker atmosphere, and lack of performance accountability”, added Omega's current account clerk (see also Hopwood, 1974).

The interviewees pointed out that the rumours of selling Omega had been circulating for a number of years. However, what demoralised people further was WW's decision to 
sell Omega to an 'evil rival' who "only wanted Omega to get/detach its technology and then close it down", according to Omega's QC (in an email). In the view of Omega's unit accountant, "morale was really at rock bottom and people wanted a takeover, such as the CC takeover, to happen". In the same vein, Omega's IT person stated, "We were open to change. The staff were willing to change-and that isn't always the case".

In summary, the extraorganisational institutional constituent, WW/parent, exerted pressures (coercive isomorphism) on Omega to adopt the group's systems, including MAS, which were inadequate enough for Omega, but adequate for the parent company. The adoption of MAS in Omega was more ceremonial than real, and the systems were merely intended to serve Group rather than be suitable for Omega. Therefore, the Omega internal systems and procedures represented Group's expectations as society-level 'rationalised' rules and procedures. Thus, Omega improved its legitimacy to WW by designing its systems and procedures in a way that symbolically reproduces 'rationality' at society (i.e., parent company) level (Meyer et al., 1983; Zucker, 1987, 1988). However, this does not mean that there was overall acceptance of the imposed systems. The systems were (partly) implemented, but not internalized (Kostova and Roth, 2002) - i.e., institutionalised. On the contrary, people were dissatisfied with them from the very beginning. It was apparent that the systems were obligatory, with "independent components that [did] not act responsively" (Orton and Weick, 1990, p. 205) and were not appropriate for internal decision-making. In practice, the actual processes at Omega did not comply with such an image, i.e., decoupling. People relied on their tacit expertise and experience to make decisions rather than on the information produced by the MIS and MAS.

\section{The dynamics of imposing/implementing CC's systems}

Due to the low staff morale in WW's time and the method adopted by CC (see below), most of the people interviewed who were involved with the takeover claimed that the takeover and implementation process was relatively smooth and did not produce tensions and disruptions normally associated with change.

To implement its programme, $\mathrm{CC}$ developed a clear strategy in which understanding the 'reality of Omega's life' (Vamosi, 2000), its people and their ways of thinking and doing things (i.e., assessing the power of system), was the base. This was achieved by increasing the extent of interaction within subsidiary (DiMaggio and Powell, 1991, p. 65) through formal and informal meetings. CC then exercised a skilful mobilisation of power and politics over Omega. In particular, through the mobilisation of its power over resources (i.e., deploying/restricting resources), over decision-making, i.e., exerting influence over the Omega members' participation in the decision-making process and in particular in 'action meeting', and over meanings and perceptions, i.e., influencing Omega members' perceptions, ideas, cognitions and preferences so that they accepted and became convinced that change was 'desirable', 'rational' and 'legitimate', CC attempted to instil its systems and "thoughts" into Omega. These three dimensions of power and the politics underpinning them are highlighted in the case study (below) as key facilitators to the process through which new (MA) systems and new accountability evolved in Omega. The following section discusses the dynamics of the takeover and the implementation of CC's systems in three phases. 


\subsection{Phase 1: preparation}

\subsubsection{Pre-takeover}

6.1.1.1. A two-way understanding, creating a strategy and a powerful steering committee. $\mathrm{CC}$ required three main objectives from the due diligence procedure which was carried out before the formal takeover. They were firstly, evaluating the profitability and the potential cost savings of Omega; secondly, achieving an understanding of 'the reality of the life' there, its people, their thoughts and taken-for-granted assumptions; thirdly, letting them know the rules of the new owner, what the new owner wants and how it works. The CC's QSE director stated that these interactions and two-way understanding (carried out after the takeover) "took a very long time, but allowed CC to pre-empt a lot of the problems that most companies experience". Having gained an overall understanding of the site CC formulated a general plan which included the desired methodology for the implementation of the new system, together with timeframes and expected outcomes and agreed objectives.

CC then held special Board Meetings called action meetings (Pixley, 2001) to review the important issues regarding the possible takeover. These issues were discussed and reviewed, and the original plan was altered as necessary. With regard to these meetings and their functions, the CC's finance director stated:

It was very much target orientated to what was necessary; to reconfirm we hadn't overlooked any key people; to identify 'who needs to do what by when'.

The meetings were initially held almost daily before becoming weekly and then monthly. As a continual monitoring exercise, the committee meetings were also held after the takeover and included the Omega people as well. Gradually, as the membership of the committee grew, it became very powerful, comprising directors and staff who had power in relation to the day-to-day implementation of the project. At these meetings, the change programme was pushed by $\mathrm{CC}$ by means of power mobilisation over decision-making processes, i.e., by exerting influence over subordinates' (the Omega staff's) participation in the decisionmaking processes. "[CC people] directed the discussions, led us to their systems, rules and policies", the IT manager commented. Although the Omega people were participating in the committee, $\mathrm{CC}$ directors dominated the process of determining what ought to be done, and what outcome should be achieved (Hardy, 1996).

\subsubsection{Post-takeover}

6.1.2.1. Developing further in-depth understanding and a strategic review. Having had a strategy in place during the pre-takeover period, $\mathrm{CC}$ planned in the post-takeover period to achieve a further in-depth understanding of people's values and taken-for-granted assumptions (i.e., power of system), in order to update its strategy regarding the change programme. "This understanding could not be achieved", as CC's director emphasised, "unless they were on site to talk and live with people", i.e., without increasing the extent of interactions (DiMaggio and Powell, 1991, p. 65) and unless CC were on site. The CC's QSE director commented:

The strategy in the first place was to try to understand what people did and understand their functions because [following] an 'acquisition', a 'merger', a 'takeover', [we]'re 
moving into an area of unknowns. [We usually] assume [that we] have knowledge or that the site [management] has knowledge, [we] assume certain controls are in place. But it's not so until [we] actually physically spend time on a site.

To develop this understanding, three interviewees stated that, CC's directors "blitzed the place!", "were over there for a good 6 months" and "basically interviewed absolutely every single person, on an informal basis", the interviewees stated. The CC's FD emphasised that by applying this method $\mathrm{CC}$ could analyse the reality and ongoing life and politics at Omega:

You go in and can't believe what's going on. I mean, it's an education for me. We've stayed over there, we've lived with them, and we're just completely with them. Then we really get to know this very quickly - the processes and who is not speaking to whom. It was amazing how quickly we did found out the politics of the company.

Regarding the difficulty of this process, which was very time consuming, CC's FD maintained:

That for me was emotionally draining and I hadn't realised how much time people were going to take. I was going to go in, put new systems in and that was it as far as I was concerned, but I must have spent like $30 \%$ on systems and $70 \%$ dealing with people, and their concerns over the takeover.

Consequently, this method provided Omega staff a better understanding of $\mathrm{CC}$ and of its expectations. As Omega's IT person commented "We were very quick to learn that if we're going to put in their systems then we do things their way; we would have to change".

CC then prepared a detailed report and carried out a strategic review. The CC's QSE director stated that it "was basically a starting 'snapshot' of what the Omega information systems and behavioural aspects were like when CC took it over", and "a comparison between technical and institutional differences between CC group and Omega".

6.1.2.2. Reorganising Omega (breaking possible resistance). At this stage, CC exercised power over 'resources', by virtue mainly of the authority derived from its position (i.e., threat of dismissal). During the first 6 months after the takeover, $\mathrm{CC}$ reorganised Omega and made a number of people redundant, including managers and employees who did not have any 'positive role' in Omega or did not subscribe to Omega's values, i.e., those who resisted change. Then, $\mathrm{CC}$ put some investment into forcing behaviour change in Omega. The CC's FD commented, "You have to be seen to be doing something for the employee, not just money. That is obviously an easy way to get people on your side". Omega's QC commented:

In order to further placate the workforce, the first capital investment in the site was to install a local ventilation system to remove noxious dusts and gases from around the reactors on the plant-something we had been asking for under WW but which was always rejected on cost grounds.

In his interpretation, this investment prepared the ground for the introduction of a new accountability and measurement system, a cultural turnaround. He added: 
This meant that morale was much improved amongst the production department, which the more cynical among us would say made it easier for CC to implement some of their more draconian measures.

In the light of staff morale in WW's time, one to one interviews and chat with CC's directors, this new investment and other physical improvement at the beginning of the takeover, people could appreciate their importance to the new owner. It was the beginning of a "cultural change" (see also DiMaggio and Powell, 1991, p. 65) and the emergence of new ways of thinking and patterns of coalition, affirmed the CC's QSE director. However, recalling staff morale in WW's time, the QSE director maintained that the employees were not on the opposite side to CC: "The assumption that they were not on our side is a wrong assumption. They were wary of us because they didn't know us". People were ready to change as they had realised Omega's situation, difficulties, and its possible closure; however, the important thing was how to construct feelings of trust for change in the planned direction (DiMaggio, 1988).

Thus, in the Omega case, pressure from CC created a new set of rules, which gradually institutionalised new values and norms in Omega; however, this institutionalisation of CC's rules and systems did not take place after 'deinstitutionalisation' (Oliver, 1992) of WW's formal rules and practices. The WW rules and systems were not institutionalised in Omega, rather, there was a fundamental questioning of the group systems and practices. Therefore, they were already delegitimised practices and procedures for the majority of the organisational members. The major weakness of Omega was the absence of a measurement culture and performance accountability. So the main CC emphasis was on introducing a cultural change rather than placing undue stress on the technical aspects of the new (accounting) systems which creates "mechanical routines" with little or no accompanying change in the taken-for-granted assumption (Burns et al., 2003). The following two sections discuss further aspects of CC's methods of bringing a cultural and institutional change to Omega.

\subsection{Phase 2: breaking established frames of meanings}

Once they had understood the prevalent organisational values and norms, in order to break the established frames of meaning and unfreezing some firmly held traditions at Omega (e.g., the absence of measurement culture and performance accountability), CC's management began an intense turnaround. In particular, $\mathrm{CC}$ pushed the change programme through by means of a mobilisation of 'power over meanings and perceptions' (Hardy, 1996) and used the staff meetings and 'discussion sessions' to convince the staff that things were not right and that change was necessary if the company was to survive. However, the emphasis was on highlighting the advantages of CC's own systems rather than other alternatives. In so doing, $\mathrm{CC}$ embarked on justifying the need for the change and on training the staff how to use the new systems and fulfil their tasks.

\subsubsection{Explaining the reasons for change and involving staff}

CC's directors hosted several formal and informal meetings to discuss the reasons for change and why the old system was not right any more. "Get them to question the taken-forgranted assumptions", the CC's FD affirmed. The usefulness of CC's systems in comparison 
to the previous one, the concepts of standard time and contribution, the importance of a culture of accountability and performance measurement together with the use of MIS and a decentralised MAS were demonstrated to the staff and the need for such change was explained. This was very important to $\mathrm{CC}$ as it helped staff to work through the process during the acquisition, to abandon their old ways of thinking and adopt the new ones, and all the while CC was gaining their commitment (Wikangas and Okumura, 1997). As CC's FD explained:

When you criticise someone about what they have been doing in the past, immediately they start to think they are obviously useless. So, with regards to that kind of thing, you have to tell them why the system they are going to use is going to be better. You have to prove that to them otherwise how do they know that they are not going down the same blind alley. [To] bring them on your side, they have to see it being useful for themselves, therefore buy-in. So, it takes a lot of convincing.

The discussion sessions consisted of up to 10 or 12 sessions with relatively small groups. The nature and purposes of the change were communicated to all relevant parties and the importance of changing the ways of thinking was fully explained and discussed. With regard to CC's takeover style, Omega's IT person commented:

It's important that we don't just say to them, right from now on you do this, you do that. That's an aggressive approach. Or you can say, we would like you to do this and this is the reason, why, and explain it to them and try and get them to understand the effects of doing something or not doing something. That's the way WE work.

$\mathrm{CC}$ increased the information load with which Omega members must contend and also developed mutual awareness (DiMaggio and Powell, 1991, p. 65). However, while people could talk and discuss openly, CC's directors dominated the processes of determining what ought to be done (mobilisation of power over meanings and perceptions) "to get CC ways and rules fully accepted". Omega's accountant argued: "Their practices, rules and systems were portrayed as the solution to our problems". CC' QSE director argued that with this policy, CC could break the established frame of meanings, change the existing values and taken-for-granted assumptions, and justify the superiority and usefulness of the new systems and rules. Moreover, according to him, this style reduced the uncertainty and the threat to individuals' sense of security (Powell, 1991) both of which cause resistance to change.

The interviewees stated that since people were informed about the change, its reasons, and values, "they were involved in what was happening", hence the implementation of the new systems went smoothly.

\subsubsection{Creating demand for the output of the change and training staff}

For CC, the next step was to create demands for the output of the new system and to furnish staff with enough information and training to fulfil those tasks. Thus, according to CC's FD, "they created the demand before bringing about the change and so people could see the change as a solution to a problem rather than an imposition of a system which itself becomes a problem". He provided an example: "Initially it was so I could use information and it was just working it through with them, so they could see how I use the information and that it was useful. [...] Then, I asked them to prepare the reports by themselves. I want 
this and this report in an hour, and at the end of this week. I want to see all of this information pulled off on these reports". The FD argued that when people were trained and informed about how to use the information, this encouraged them to use the information and take ownership of the change.

\subsection{Phase 3: adopting an autocratic management style to implement the change}

Due to the 'technical and people-oriented management style within CC', people are deemed to be important and are considered key players. However, it should be made clear that while decisions were made and there were no justifications for altering them, there would be no chance for any delays or unexpected changes from the plan. The CC's OD explained that after justifying the reasons for the change and after training staff, CC's directors (by virtue mainly of the authority derived from CC's position) were very strict in implementing the system and "there wasn't an opportunity for debate", as several interviewees affirmed. The CC's QSE stated, "It was imposed in a style as being democratic-autocratic really. People were involved, but at the end of the day that was [CC's plans]". Elaborating on this sort of management style, he commented, "It was democratic since CC explained the present situation and justified the need for change, and let people talk and discuss what they thought was relevant to the improvement of the system. And it was autocratic, since if a decision was made and finalised, no delays and changes in the plan were acceptable, except reasonable ones".

Omega's IT person argued, "There was such an authority supporting the change plan that everybody knew that it had to be done". Discussing the possibility of any resistance to change, he explained, "If we didn't change, we couldn't be here. It was that aggressive. That's how it was portrayed to us. People were very quick to learn that they had to change". He argued, "people were frightened, there was a latent threat, but the method that CC employed to justify the change could bring people onto its side". He concluded:

And I'd say it was smooth, but we made it smooth. We did a lot of work during the takeover to get the information to them, to the right people when they wanted it. But there was always a threat above us.

The two-step approach adopted by $\mathrm{CC}$, justifying the need for change and adopting an autocratic management style, to break established frames of meanings in Omega and implement its own systems is consistent with the findings of a questionnaire study undertaken by Jones (1992) in 17 taken over companies. Jones's study reveals that the explanation and justification of the change programme before it is imposed has a major impact on the successful imposition of the change programme in M\&A and management buyouts. Consistent with the latter step, his study's findings also confirm that at a time of crisis such as under M\&A and MBO, "a more assertive style of management [is] perceived as relevant to the management of crisis" and can lead to a successful change programme (p. 165).

Thus, while this study breaks the actions down in order to enable more sense to be made of them, the actions taken by CC to impose its systems and rules represented a careful, coordinated, integrated strategy, in which the mobilisation and targeting of all three 'facilitating' dimensions of power reinforced each other (Hardy, 1996, p. S13). It has been argued that 'resource' power and the power of 'decision-making' are typically insufficient 
by themselves to bring about institutional change (see Burns, 2000a). CC's emphasis was more on facilitating institutional change by means of mobilising "power over meanings and perceptions' and appealing to normative "visions", instead of openly prescribing the change (Collins and Porras, 1991). This had an impact on the meanings through which the Omega members perceived things, and moulded their performances in such a way that taken-forgranted assumptions and beliefs (e.g., lack of accountability) were increasingly questioned. The organisational members and change agents were made to understand fully the purpose behind the new MIS, MAS, and new accountability. As Burns (2000a, p. 33) notes, without such understanding it is unlikely that the old meanings will be questioned and new meanings emerge and, consequently, it is unlikely that institutional changes will take place.

When staff were informed about the plans and decisions, (the whys), and were taught to fulfil their tasks, and "logics of action" were formed (Hinings et al., 1996), (the hows), the organisational culture (or 'climate' as Hinings et al., 1996, state) became disposed to adopt the new systems. Therefore, although many other studies suggest that the acceptance of new systems usually comes after the adoption, in the Omega case this acceptance occurred and the "fruits" (Klein and Sorra, 1996) were apparent there before the adoption of CC's systems. Consequently, the method adopted by $\mathrm{CC}$ fostered the new system use by (a) ensuring employees were skilled in the new system use (i.e., training), (b) providing incentives for its use and disincentives for avoidance (i.e., creating demands for outputs and results), and (c) removing obstacles to its use (i.e., adopting an autocratic style) (Klein and Sorra, 1996). Interestingly, to bring people along with the group strategy and to implement the change successfully, CC did not pay any reward or compensation as suggested by some researchers (see Shields, 1995). The CC's FD maintained that since staff is expected to carry out their responsibilities, there is no bonus payable as a result of simply carrying out basic responsibilities. Similarly, the CC's QSE director comments, "motivating people is important for business success, but it doesn't come just by reward, bonuses and pay. There are other psychological issues such as security or longevity and these sorts of issues are important and people need them. These are "exactly what CC brought to them".

In summary, $\mathrm{CC}$ had worked on the cultural side of the change in Omega so that when the new rules and systems were introduced the existing values and institutions at micro (subsidiary)-level were already changing in a manner that was compatible with the underlying assumptions of $\mathrm{CC}$ ways and accountability. Furthermore, the justification prior to implementation minimised conflict due to common, rather than conflicting interests (Collier, 2001). Moreover, the positive perceptions about the value of the new systems became "action-generating properties that facilitate not only the initial adoption of the practice but also its persistence and stability over time" (Kostova and Roth, 2002, p. 217; see also Tolbert and Zucker, 1996). As a result, the revolutionary change was perceived to be smooth, as the interviewees maintained.

In order to routinise the changes imposed by authority (i.e., coercive isomorphism), Omega undertook mimetic isomorphism and modelled itself on the parent company's structure and systems (Abernethy and Chua, 1996). However, this mimetic isomorphism was not due to 'uncertainty' (cf. Abernethy and Chua, 1996; DiMaggio and Powell, 1983; Scott, 1987, 1991; Tolbert and Zucker, 1983), or to fads and fashions (cf. Carruthers, 1995). Because the parent company had worked on the cultural aspect of the change and reformed the prevalent perceptions and meanings in line with the new systems prior to initiating 
the change, the new systems and practices were seen as solutions to the existing problems of Omega. For this reason, the radical and revolutionary change met with less resistance and occurred rapidly. Consequently, the parent company's (MA) systems, rules, and expectations of appropriate organisational form and behaviour gradually become embedded in Omega's routines resulting in shared understandings about the importance of accountability to the firm and, over time, these company systems came to take on rule-like states in the thoughts and actions of subsidiary organisational members (Covaleski and Dirsmith, 1988). In other words, as people accepted and trusted CC rules and acted upon them, these repeated actions and behaviours led to either a conscious or unconscious reproduction of routines which gradually over time became 'simply the way things are, i.e., institutions' (Burns and Scapens, 2000). Thus, CC's 'rationalised' rules and procedures (e.g., MAS) that define 'institution' at the macro (extra-Omega)-level, as indicated in NIS theory, became integral to Omega's internal structures and processes, and formed institutions at the micro (intra-Omega)-level, as indicated in OIE theory as discussed in the theoretical section.

\section{A redefined company}

Omega is no longer a bureaucratic company with poor performance. "It is the most profitable in the group" several interviewees affirmed. Omega appeared to accept the legitimacy of the new forms of accountability and welcomed an MAS which was consistent with accounting procedures elsewhere in the group. This isomorphism to parent company systems made Omega a byword for stability and conservatism. In a short space of time, Omega developed a new respect for accounting information (Bhimani and Pigott, 1992; Soin et al., 2002) and new accounting routines were developed, for example, producing contribution-based performance reports. MA is something managers and staff largely do for themselves, with the help and guidance of the CC's FD and the role of management accountant is mainly preparing information for group's account.

Under the management of $\mathrm{CC}$, there has been a fundamental cultural change in Omega. People know the rules and what they do and why. They know how important their roles are and they are certain of being questioned further if things do not go well, unless there is a convincing reason. The concepts of time and contribution are taken-for-granted assumptions and common organisational language; also, with the proper flow of information, performance is frequently monitored and evaluated. Furthermore, when people are aware of their roles and are justified in doing what they do (the why and how), staff are more accountable, empowered and creative. Moreover, they constantly strive for an 'improvement of standards', something which has become routine and which is taken for granted in Omega. They have attained a culture of change, which makes them more confident about their jobs. There is no feeling that a second tier of people exists in the company; the hierarchy and the staff are integrated as a team and the previous ' $\mathrm{I} / \mathrm{me}$ ' philosophy has turned into a 'we' philosophy. Customers' satisfaction is extremely important and therefore quality and on-time delivery are constantly kept under control, for the company has become customer oriented. However, this change has not happened in 1 day, but over a period of time.

In the new institutional setting, MAS has played a principal and disciplinary role in constituting Omega, making visible the reality of everyday life, and supporting the creation 
of a new identity (Vamosi, 2000), of which employees are proud, as several interviewees confirmed. The new MAS was central to the whole system implemented in Omega, which succeeded in reaping significant improvements in multi-client business, and the company surmounted the danger of its lock-in towards captive work. Thus, the new MAS affected change in Omega staff members' ways of thinking about the business and instilled in them a "money-orientation" belief, expressed in terms of 'contribution', a phrase used by several interviewees. This became the "dominating rationality or core belief" (Pettigrew, 1985) and a part of the dominant routines and institutions within Omega, articulated through structural design and organisational processes (Hinings et al., 1996).

\section{Summary and discussion}

The study now draws the narrative together by discussing the findings in relation to the following three questions of interest:

- To what extent and how do parent companies impose their own systems on subsidiaries?

- How important are (local) political, cultural and institutional factors in shaping the dynamics of the implementation of change?

- How new systems and practices become accepted and take root as values and beliefs and how they supplement earlier norms?

The Omega case demonstrates that its MAS/MIS are a function of the organisation's institutional environment. Omega had its systems imposed by its parent companies. WW implemented its own systems and after CC's takeover, the new owner did the same. Both WW and CC thus imposed their systems on Omega.

In the Omega case, because of the clear weaknesses of the WW's systems and their conflicts with employees' willingness, the parent company's rules and systems were questioned. However, Omega's (MA) systems had to meet the expectations and stipulations of the parent company, even if this meant installing unsuitable systems. Therefore, the use of these systems/MAS provided Omega with legitimacy in its field rather than with efficient information for decision-making. The production and display of MA reports, which were consistent with the parent company's policies and the reliance of decision makers on information provided by other sources, such as personal experience, are consistent with the terms of 'decoupling' or 'masking' in NIS theory (Oliver, 1991; Scott, 1983; Zucker, 1983). This was the result of incompatibilities between institutional and technical pressures. Meyer and Rowan (1977, p. 341) noted that organisations respond to this contradiction by buffering, building gaps between formal structures from actual work activities in order to maintain "ceremonial conformity" (see also Orton and Weick, 1990, p. 207 for further discussion). In contrast, during the time that $\mathrm{CC}$ had control of Omega, the new owner's (MA) systems and rules were transmitted to Omega, were widely accepted, then implemented and tightly coupled (Orton and Weick, 1990). Furthermore, another major change within Omega concerned measurement and accountability, for Omega had no tradition of widespread performance measurement systems. This formal change occurred by conscious design, through the introduction of new rules by the parent company (see Burns and Scapens, 2000; Rutherford, 1994). 
$\mathrm{CC}$ was able to implement its systems within about 9 months and the revolutionary institutional (cultural) change was accomplished within about 3 years. During that time, Omega changed from being a company with little tradition of measurement-based management control systems and poor performance, to a fully integrated part of CC managed in the CC way which relies on measurement system. To plan for the change, $\mathrm{CC}$ through 'increasing the extent of interaction' prepared for a full understanding of Omega, an otherwise 'unknown area', of its day-to-day operations, routines, values, taken-for-granted assumptions, institutions and culture. Based on this understanding of the intra-organisational dynamics and the 'reality of life' in Omega, CC established a strategy for the takeover and the implementation of its own systems there. As the new owner, CC relied on its fresh authority to reorganise and 'define the inter-organisational structures of domination and patterns of coalition' and meanwhile attempted to convince the staff regarding the necessity for change and the benefits of the new systems. It was beginning to form "logics of action" (Hinings et al., 1996).

The change was justified to staff by holding several meetings (both formal and informal) at which people were encouraged to participate in the discussion of the issues. At this point CC 'increased the information load with which the Omega members must contend' and also 'developed a mutual awareness among participants' to form new "meaning and perception". These processes taken by CC to institutionalise its rules and systems within Omega are consistent with NIS argument. According to DiMaggio and Powell:

The process of institutional definition, or "structuration", consists of four parts: an increase in the extent of interaction among organizations in the field; the emergence of sharply defined inter-organizational structures of domination and patterns of coalition; an increase in the information load with which organizations in a field must contend; and the development of a mutual awareness among participants in a set of organizations that they are involved in a common enterprise. Once disparate organizations in the same line of business are structured into an actual field [...], powerful forces emerge that lead them to become more similar to one another (DiMaggio and Powell, 1991, p. 65).

Thus, CC's successful implementation of its plan was mainly because of its attention to the values and taken-for-granted assumptions in Omega and its attempts to achieve congruence between the institutional context and the new systems and practices. Being aware that the interests of organisational actors do 'matter' (Abernethy and Chua, 1996; Collier, 2001) and that change had to be accepted by the existing network, CC employed the other three dimensions of power ('resources', 'decision-making process' and 'meanings and perceptions') against the power of the system to bring about institutional change (Hardy, 1996). In particular, the emphasis was on facilitating institutional change by means of the mobilisation of power over meanings. Namely, by affecting the manner in which organisational members perceive things, or by moulding their preferences in such a way that the taken-for-granted assumptions and beliefs were increasingly questioned. Consequently, the parent company systems and rules gradually became embedded in the subsidiary routines.

In summary, the internal workings of the subsidiary company are influenced by interrelated forces, both inside and outside the organisation. As such, the existing institutions in a subsidiary organisation are influenced, sustained, and changed by the socio-economic 
(parent) context in which the subsidiary organisation is located. History can shape the persistence and change of institutions in a subsidiary organisation. Therefore, the change or lack of change, the pace and the direction of change in subsidiary companies seem to depend on the context of the organisation (the strength and forms of the parent companies' pressure) and also on the strength and durability of the institutions at micro (subsidiary company)-level, i.e., the power of system. Similarly, Greenwood and Hinings (1996) argue that a change of system depends on harmonisation between intra- and extra-organisational factors. This is also possible when one source of power, or a coalition of powers, becomes sufficiently strong to coerce others (Greenwood and Hinings, 1996). Thus, the processes which led to projects being implemented, diverted, or abandoned are "complex and grounded in the specific context and history of the company" (Burns and Scapens, 2000, p. 16). Furthermore, any analysis of "these factors [has] to be seen in the specific context and history" (Burns and Scapens, 2000) of subsidiary organisations.

NIS theory is said to assume that "practices designed to secure external legitimacy are only symbolic and always decoupled from internal operating systems" (Abernethy and Chua, 1996, p. 572; see also Zucker, 1987, 1988). In other words, conformity to societal rules and procedures, such as parent companies' policies and systems, always conflicts with efficiency criteria in the subsidiary organisations (cf. Carruthers, 1995; Chua, 1995; Mouritsen, 1994). However, the Omega case presents conflicting results.

The Omega case at the time of WW conformed to the above assumption. The case indicates that when there is a conflict between external reporting and internal information requirements, the subsidiaries produce and display MA reports consistent with parent companies' accounting policies and meanwhile rely on the information provided by other sources, such as staff's personal experience, for decision-making. Therefore, the subsidiary organisations decoupled their formal structures from their actual work activities (Meyer and Rowan, 1991) to "accommodate conflicting demands" (Collier, 2001, p. 470). However, in the Omega case at the time of $\mathrm{CC}$, when there was consistency between external reporting and internal information requirements, the formal structure of the subsidiary was coupled with its actual work activities and simultaneously the subsidiary gained external legitimacy (Orton and Weick, 1990). Thus, drawing on the case study of one subsidiary company under the discipline of two parent companies, we find that practices designed to secure external legitimacy are not always symbolic and decoupled from internal operating systems. The decoupling may occur if (subsidiary) organisations face conflicting, inconsistent demands about what structures and practices they ought to use to be able to maintain legitimacy. Thus, NIS researchers should consider this for further development of the theory.

Furthermore, despite Scott's (1987) contention that changes imposed by authority are less superficial and less loosely coupled to participant activities, the Omega case at the time of WW shows that although MAS were imposed by the parent companies (authority), they were decoupled from subsidiary organisational activities. Thus, changes imposed by authority may result in a decoupling.

The Omega case study provides insight into the way internal participants respond to external pressures. This investigation has shown that organisational actors have an active role in organisations' responses to institutional environments. Few researchers have so far investigated this area but they analysed it from the viewpoint of NIS theory. The Omega case study reinforces the need for a shift towards more pluralistic dialogue and multi-institutional 
theoretical outlooks for studying MA in practice. The case study indicates that no single institutional theory, neither NIS nor OIE, can conceptualise and explain the mechanics and complexities of MA change in a (subsidiary) organisation. NIS tends to focus on 'macro'institutions (e.g., parent) in legitimising organisations and their structures, at the expense of studying processes at a micro (organisational)-level (Carruthers, 1995; Zucker, 1991) while OIE focuses on 'micro'-institutions within organisations and deals more directly with the emergence, continuity, and change of institutions over time. This study has proposed that a holistic study of organisational change (e.g., MAS) requires a "pluralistic/hybrid" framework which addresses the limitations of NIS and OIE. In doing so, the study has attempted to move forward with pluralistic (multi-institutional) dialogue, which incorporates both NIS and OIE based on common research themes (see for example Collier, 2001; Modell, 2001) in order to shed some light on understanding MA change. Although a start has been made, the case study shows that much remains to be done concerning the interface between macroand micro-orders.

The particular feature of the Burns and Scapens' framework, which made it especially relevant for understanding process of change in Omega, is that it focuses attention on institutions within the firm. Nevertheless, the impact of external institutions, such as parent companies, cannot be ignored in seeking to understand MA change. It is the interaction of internal and external institutions that shape MA change within (subsidiary) organisations. Thus, Burns and Scapens' (2000) framework needs further development to accommodate the interaction of external (macro-level) institutions such as parent companies and internal (micro-level) institutions.

Furthermore, the above case study adds weight to the argument that conventional wisdom is too simplistic to be practically useful in the actual implementation of (accounting) change. The practical (MA) change should take into account the importance of power, politics, and culture in facilitating or preventing change.

In exploring the relationship between extra-Omega institutional factors (CC) and MAS, the case highlights how new forms of accountability emerged and became institutionalised: in other words, the case provided some insights into "institutionalisation in the making" (Abernethy and Chua, 1996). It supports Gouldner (1954) contention that new institutional norms and beliefs have never developed without the intervention of self-interested and powerful groups such as parent companies (Abernethy and Chua, 1996). According to NIS, MA change normally occurs when it has become necessary to conform to changes that are taking place externally such as at the parent company's level (Burns and Scapens, 2000).

Consistent with Yazdifar and Tsamenyi (2005), Burns and Yazdifar (2003) and Abernethy and Chua (1996), the Omega case provides some interesting insights into the role of the MAS in the overall accounting system in group organisations. The case suggests that subsidiary organisations may not need to invest in highly sophisticated accounting systems to meet the parent company's demands for legitimacy and efficiency. A "crude" costing system with approximation may be a sufficient substitute for "sophisticated" cost controls and MAS.

In addition to the MAS, the role of the 'management accountant' was also affected by the two parent companies. In Omega, in WW's time, when MAS information did not play any significant role in the organisation's decision-making, because managers relied on their tacit expertise and other sources of information for decision-making, the Omega (management) accountant was responsible for budgeting and consolidating management 
accounts for reporting to Group. In contrast, in Omega in CC's time, when MAS information was spread across the organisation and was informative to managers for their day-to-day decision-making, and allowed them to analyse management accounts by themselves, the (management) accountant role was to make sure that Omega's accounts were in line with Group's policy, with the CC way. Therefore, in addition to MAS, the role of the management accountant in the subsidiary company was also affected by its parent companies. This may imply the need for new forms of education and training for management accountants working in group organisations and the development of research, learning, and problem solving skills.

The results of this study in a subsidiary company did not support claims that institutional pressures are primarily confined to public and not-for-profit organisations (see also Burns and Yazdifar, 2003; Major and Hopper, 2002). This case study of a private sector firm pursuing profit objectives revealed that they, too, face institutional pressures. However, the company cases in this study are operating in chemical industry, as part of a societal sector (defined to include all organisations within a society supplying a given type of product or service together with their associated organisational sets: suppliers, financiers, regulators, and so forth), and institutional pressures in this industry and sector might be different from other sectors (Scott and Meyer, 1983, 1991).

Moreover, the Omega case study sheds some light on the issue of whether or not efficiency and institutional pressures are dichotomous. Zucker (1987, p. 445) argues that some institutionalists believe: "Organizational conformity to the institutional environment simultaneously increases positive evaluation, resource flows, and therefore survival chances, and reduces efficiency". However, Meyer and Rowan (1977, 1991) noted that legitimacy need not be gained inevitably at the expense of efficiency, and vice versa. In contrast to Meyer and Rowan's argument, the Omega situation in WW's time weakens the view that efficiency and institutional pressures are not dichotomous. The study highlights the fact that the legitimacy of MAS (and other Omega systems) was gained at the expense of efficiency. Omega would not have obtained legitimacy from its external constituency, WW, had its (MA) systems not been similar to that of the parent company. However, the Omega situation in CC's time supports Meyer and Rowan's (1977) view that efficiency and institutional pressures are not dichotomous, since legitimacy was not gained at the expense of efficiency. Thus, it has been observed that efficiency and institutional pressures may or may not be dichotomous, even in a particular organisation under different parent companies' control.

Finally, a brief discussion of possible implications of the Omega case for future accounting research. First, additional use of the adopted "multi-institutional theory" and processual approach is recommended to analyse the dynamics of parent-subsidiary relationships over time. Such studies should result in a more holistic understanding of the emergence, continuity and/or change in accounting forms and accountability that can emerge following mergers and acquisitions. Second, the reliance on tacit knowledge at the operating level in the face of inconsistent, institutional systems is a potentially interesting theme for further analysis. The link between institutional processes and this form of knowledge and decision-making heuristics and how these respond to the introduction of new MA techniques have not been extensively studied within institutional theory and might carry the analysis beyond the simplistic interpretation of organisational decoupling prevailing in much prior NIS research. Indeed, as Orton and Weick (1990, p. 204) pointed out, some researchers have invoked 
the concept of coupling, loose-coupling or loosely coupled and decoupling (see Glassman, 1973; Weick, 1976, 1982a, 1982b) however, "few researchers have questioned the meaning beyond these statements". Third, this paper was concerned with group organisations operating in the chemical industry as part of a societal sector. However, as noted by Scott and Meyer (1991, p. 137), "societal sectors vary in many important respects" and therefore this case may not be applicable to all sectors.

\section{Acknowledgements}

The helpful comments of Bob Scapens, John Burns, Trevor Hopper, Sue Richardson and John Cullen are acknowledged. We are also grateful to the two anonymous reviewers for their constructive comments and suggestions.

\section{References}

Abernethy MA, Chua WF. A field study of control systems 'redesign': the impact of institutional processes on strategic choice. Contemporary Accounting Research 1996;13:569-606.

Babbie E. The practice of social research. 5th ed. Belmont, CA: Wadsworth Publishing; 1989.

Berry AJ, Capps T, Cooper D, Ferguson P, Hopper T, Lowe EA. Management control in an area of the NCB: rationales of accounting practices in a public enterprise. Accounting, Organizations and Society 1985:3-28.

Bhimani A, Pigott D. Implementing ABC: a case study of organizational and behavioural consequences. Management Accounting Research 1992;3:119-32.

Buchanan D, Badham R. Power, politics and organizational change: winning the turf game. London: Sage Publication; 1999.

Burns J. The dynamics of accounting change: inter-play between new practices, routines, institutions, power and politics. Accounting, Auditing and Accountability Journal 2000a;13(5):566-96.

Burns J. Institutional theory in management accounting research: the past, the present, and the future. In: Paper presented in ENROAC conference, conference proceedings; 2000b.

Burns J, Ezzamel M, Scapens RW. The challenge of management accounting change: behavioural and cultural aspects of change management. CIMA Monogragh 2003.

Burns J, Scapens RW. Conceptualizing management accounting change: an institutional framework. Management Accounting Research 2000;11:3-25.

Burns J, Yazdifar H. Dependent -v- independent companies: some evidence on roles of the accountant. Working paper. University of Sheffield; 2003.

Carmona S, Ezzamel M, Gutiérrez F. Towards an institutional analysis of accounting change in the royal tobacco factory of seville. Accounting Historians Journal 1998;25(1):115-47.

Carpenter VL, Feroz EH. GAAP as a symbol of legitimacy: New York state's decision to adopt generally accepted accounting principles for external financial reporting. Accounting, Organisations and Society 1992;17(7):613-43.

Carruthers BG. Accounting, ambiguity, and the new institutionalism. Accounting, Organizations and Society 1995;20(4):313-28.

Chua WF. Experts, networks and inscriptions in the fabrication of accounting images: a story of the representation of three public hospitals. Accounting, Organisations and Society 1995;20:111-45.

Collier PM. The power of accounting: a field study of local financial management in a police force. Management Accounting Research 2001;12:465-86.

Collins JC, Porras JI. Organizational vision and visionary organizations. California Management Review 1991;34(1):30-52.

Covaleski MA, Dirsmith MW. An institutional perspective on the rise, social transformation, and fall of a university budget category. Administrative Science Quarterly 1988;33:562-87. 
Covaleski MA, Dirsmith MW, Michelman IE. An institutional theory perspective on the DRG framework, casemix accounting systems and health-care organizations. Accounting, Organisations and Society 1993;18(1): 65-80.

Dietrich M, Burns J. Industrial policy, industrial change and institutional inertia. In: Groenewegen J, Elsner W, editors. Industrial policy. Kluwer; 2000.

Dillard JF, Rigsby JT, Goodman C. The making and remaking of organization context: duality and the institutionalization process. Accounting, Auditing and Accountability Journal 2004;17(4):506-42.

DiMaggio P. Interest and agency in institutional theory. In: Zucker LE, editor. Institutional patterns and organizations: culture and environment. Cambridge, MA: Ballinger; 1988. p. 3-21.

DiMaggio PJ, Powell WW. The iron cage revisited: institutional isomorphism and collective rationality in organizational fields. American Sociological Review 1983;48:147-60.

DiMaggio PJ, Powell WW. The iron cage revisited: institutional isomorphism and collective rationality in organizational fields. In: Powell WW, DiMaggio PJ, editors. The new institutionalism in organizational analysis. Chicago: The University of Chicago Press; 1991. p. 63-82.

Fligstein N. Reviewed work: "institutional patterns and organizational: culture and environment". In: Zucker LG, editor. Administrative Science Quarterly 1989;34(3):501-3.

Glassman RB. Persistence and loose coupling in living systems. Behavioral Science 1973;18:83-98.

Gouldner AW. Patterns of industrial bureaucracy. Glencoe, IL: Free Press; 1954.

Granlund M. Management accounting integration in corporate mergers: a case study. Accounting, Auditing and Accountability Journal 2003;16(2):208-43.

Greenwood R, Hinings CR. Understanding radical organizational change: bringing together the old and the new institutionalism. Academy of Management Review 1996;21(4):1022-54.

Hamilton WH. Institution. In: Seligman ERA, Johnson A, editors. Encyclopaedia of Social Science 1932;73(4):560-95.

Hardy C. Understanding power: bringing about strategic change. British Journal of Management 1996;7:S3-16 [special issue].

Hinings CR, Thibault L, Slack T, Kikulis LM. Values and organizational structure. Human Relations 1996;49(7):885-916.

Hodgson G. Institutional economics: surveying the old and the new. Metroeconomica 1993;44:1-28.

Hopwood AG. Leadership climate and the use of accounting data in performance evaluation. The Accounting Review 1974;49(3):485-95.

Johanson J, Vahlne JE. The internationalization process of the firm - a model of knowledge development and increasing foreign market commitments. Journal of International Business Studies 1977;8: 23-32.

Jones CS. An empirical study of the role of management accounting systems following takeover and merger. Accounting, Organisations and Society 1985;10(2):177-200.

Jones CS. The attitudes of owner-managers towards accounting control systems following management buyout. Accounting, Organisations and Society 1992;17(2):151-68.

Klein KJ, Sorra S. The challenge of innovation implementation. Academy of Management Review 1996; 21(4):1055-80.

Kostova T, Roth K. Adoption of an organizational practice by subsidiaries of multinational corporations: institutional and relational effects. Academy of Management Journal 2002;45(1):215-33.

Major MJMF, Hopper T. Extending new institutional theory: a case study of activity-based costing in the Portuguese telecommunications industry. Working paper; 2002.

Meyer JW, Rowan B. Institutionalised organisations: formal structures as myth and ceremony. American Journal of Sociology 1977;83:340-63.

Meyer JW, Rowan B. Institutionalised organisations: formal structures as myth and ceremony. In: Powell A, DiMaggio PJ, editors. The new institutionalism in organizational analysis. Chicago: The University of Chicago Press; 1991. p. 41-62.

Meyer JW, Scott WR, Deal TE. Institutional and technical sources of organization structure: explaining the structure of educational organization. In: Meyer JW, Scott WR, editors. Organizational environments: ritual and rationality. Beverly Hill, CA: Sage; 1983. p. 45-67.

Mezias SJ. An institutional model of organizational practice: financial reporting at the fortune 200. Administrative Science Quarterly 1990:431-57. 
Modell S. An institutional perspective on cost allocations. In: Paper presented at the third workshop on management accounting change; 2001.

Mouritsen J. Rationality, institutions and decision making: reflections on March and Olsen's rediscovering institutions. Accounting, Organisations and Society 1994;19-20:193-211.

Nelson RR, Winter SG. An evolutionary theory of economic change. Belknap Harvard; 1982.

Oliver C. Strategic responses to institutional processes. Academy of Management Review 1991;16(1):145-79.

Oliver C. The antecedents of deinstitutionalization. Organization Studies 1992;13(4):563-88.

Orton D, Weick KE. Loosely coupled system: a reconceptualization. Academy of Management Review 1990;15(2):203-23.

Pettigrew AM. The awakening giant: continuity and change at ICI. Oxford: Blackwell; 1985.

Pettigrew A, McNulty T. Power and influence in and around the boardroom. Human Relations 1995;48:845-73.

Pfeffer J. Managing with power: politics and influence in organizations. Boston, MA, USA: Harvard Business School Press; 1992.

Pixley M. Organisational transformation and methods for change; 2001, http://www.leadershipinc.com. cn/articles/OrgTrans.pdf.

Powell WW. Expanding the scope of institutional analysis. In: Powell WW, DiMaggio PJ, editors. The new institutionalism in organizational analysis. Chicago: The University of Chicago Press; 1991. p. 183-203.

Rutherford M. Institutions in economics: the old and new institutionalism. Cambridge: Cambridge University Press; 1994.

Scapens RW. Management accounting: a review of recent developments. 2nd ed. Macmillan; 1991.

Scott WR. The organization of environments: network, cultural, and historical elements. In: Meyer JW, Scott WR, editors. Organizational environments: ritual and rationality. Beverly Hill, CA: Sage; 1983. p. 155-75.

Scott WR. The adolescence of institutional theory. Administrative Science Quarterly 1987;32:493-511.

Scott WR. Unpacking institutional arguments. In: Powell WW, DiMaggio PJ, editors. The new institutionalism in organizational analysis. Chicago: The University of Chicago Press; 1991. p. 164-82.

Scott WR. Institutions and organizations. 2nd ed. Thousand Oaks, CA: Sage; 2001.

Scott WR, Meyer JW. The organization of societal sectors. In: Meyer JW, Scott WR, editors. Organizational environments: ritual and rationality. Beverly Hill, CA: Sage; 1983. p. 129-53.

Scott WR, Meyer JW. The organization of societal sectors: propositions and early evidence. In: Powell A, DiMaggio PJ, editors. The new institutionalism in organizational analysis. Chicago: The University of Chicago Press; 1991. p. 108-40.

Shields MD. An empirical analysis of firms' implementation experiences with activity-based costing. Journal of Management Accounting Research 1995(Fall):148-65.

Siti-Nabiha AK, Scapens RW. Stability and change: an institutionalist study of management accounting change. Accounting, Auditing \& Accountability Journal 2005;18(1):44-73.

Soin K, Seal W, Cullen J. ABC and organizational change: an institutional perspective. Management Accounting Research 2002;13:249-71.

Tolbert PS, Zucker LG. Institutional sources of change in the formal structure of organizations: the diffusion of civil service reforms, 1880-1935. Administrative Science Quarterly 1983;28:22-39.

Tolbert PS, Zucker L. The institutionalization of institutional theory. In: Clegg SR, Hardy C, Nord W, editors. Handbook of organizational studies. Thousand Oaks, CA: Sage; 1996. p. 175-90.

Vamosi TS. Continuity and change; management accounting during processes of transition. Management Accounting Research 2000;11:27-63.

Vernon R. International investments and international trade in the product cycle. Quarterly Journal of Economics 1966;80:190-207.

Weick KE. Educational organizations as loosely coupled systems. Administrative Science Quarterly 1976;21:1-19.

Weick KE. Management of organizational change among loosely coupled elements. In: Goodman PS, et al., editors. Change in organizations. San Francisco: Jossey-Bass; 1982a. p. 375-408.

Weick KE. Administering education in loosely coupled schools, No. 63. Phi Delta Kappan; 1982b. p. 673-6.

Wikangas L, Okumura A. Why do people follow leaders? A study of a U.S. and a Japanese change program. The Leadership Quarterly 1997;8(3):313-37.

Yazdifar H, Tsamenyi M. Management accounting change and the changing roles of management accountants: a comparative analysis between dependent and independent organisations. Journal of Accounting and Organizational Change 2005;1(2):180-98. 
Zucker LG. Organizations as institutions. In: Bacharach SB, editor. Research in the sociology of organizations. 2nd ed. Greenwich, CT: JAI Press; 1983. p. 1-47.

Zucker LG. Institutional theories of organizations. Annual Review of Sociology 1987;13:443-64.

Zucker LG. Where do institutional patterns come from? Organizations as actors in social systems. In: Zucker LE, editor. Institutional patterns and organizations: culture and environment. Cambridge, MA: Ballinger; 1988. p. 23-52.

Zucker LG. The role of institutionalization in cultural persistence. In: Powell WW, DiMaggio PJ, editors. The new institutionalism in organizational analysis. Chicago: The University of Chicago Press; 1991. p. 83-107. 